\title{
Characterization of Human AB Serum for Mesenchymal Stromal Cell Expansion
}

\author{
Vanessa Tieko Marques dos Santos ${ }^{a} \quad$ Amanda Mizukami ${ }^{a} \quad$ Maristela Delgado Orellana ${ }^{a}$ \\ Samia Rigotto Caruso ${ }^{a}$ Fernanda Borges da Silva $^{b}$ Fabiola Traina $^{b}$ Karen de Lima Prata ${ }^{a}$ \\ Dimas Tadeu Covas ${ }^{a, b}$ Kamilla Swiech ${ }^{a, c}$ \\ ${ }^{a}$ Center for Cell-Based Therapy, Blood Center of Ribeirão Preto, Ribeirão Preto Medical School, University of São Paulo, Ribeirão Preto, \\ Brazil;

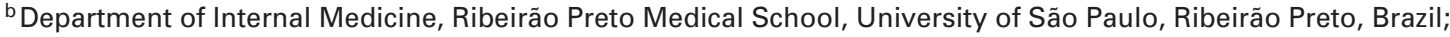 \\ ${ }^{c}$ Department of Pharmaceutical Sciences, School of Pharmaceutical Sciences of Ribeirão Preto, University of São Paulo, Ribeirão Preto, \\ Brazil
}

\section{Keywords}

Mesenchymal stromal cells - Fetal bovine serum . Human AB serum . Cell expansion

\section{Summary}

Background: So far, using human blood-derived components appears to be the most efficient and safest approach available for mesenchymal stromal cell (MSC) expansion. In this paper, we report on the characterization of human $A B$ serum ( $A B$ HS) produced by using different plasma sources, and its use as an alternative supplement to MSC expansion. Methods: Two plasma sources were used for $A B$ HS production: plasma removed from whole blood after $24 \mathrm{~h}$ of collection (PC $>24$ h) and plasma, cryoprecipitate reduced (PCryoR). The biochemical profile and quality of the produced $A B \mathrm{HS}$ batches were analyzed and their ability to support MSC cell growth after different storage times $(0,3,6,9$ and 12 months) was evaluated. Results: The two plasma sources used showed similar characteristics regarding biochemical constituents and quality parameters and were effective in promoting MSC growth. MSCs cultured in medium supplemented with $10 \%$ AB HS presented similar doubling times and cumulative population doublings when compared to the $10 \%$ fetal bovine serum(FBS)-supplemented culture while maintaining immunophenotype, functional features, and cytogenetic profile. Conclusion: Overall, the results indicate that $A B$ HS is an efficient FBS substitute and can be used for at least 12 months after production without impairing cell proliferation and quality.

(C) 2016 S. Karger GmbH, Freiburg

\section{Introduction}

Mesenchymal stromal cells (MSCs) have been used in a large number of clinical trials due to their immunomodulatory and regenerative properties. As the levels at which these cells are present in tissues are low, these therapies require large-scale good manufacturing practice(GMP)-compliant expansion processes. The medium used for the cell culture is a key compliance factor [1,2]. Although effective, the use of fetal bovine serum (FBS), which is currently the standard supplement for cell expansion, or other animalderived components is highly discouraged by regulatory agencies due to the risk of transmitting xenogenic infectious agents and immunization [3, 4]. Additional disadvantages of FBS include its scarcity, batch-to-batch variations impacting culture reproducibility, and ethical concerns [1]. Therefore, the scientific community has proposed FBS alternatives. Chemically defined supplements successfully used to produce recombinant therapeutic proteins have not yet proved to be effective to support MSC growth. Using human blood-derived components such as human serum (autologous or pooled allogeneic), umbilical cord blood serum, and platelet products seems to be the most efficient and safest approach available so far $[1,5]$. The potential risk of these products is reduced because human blood components have been in clinical use for years. They are derived from healthy blood donors and tested according to blood bank standards for infectious and immunological parameters [5].

Among the blood-derived components, human $\mathrm{AB}$ serum $(\mathrm{AB}$ HS) can be considered a promising FBS alternative due to its availability and possibility of autologous usage [6]. Various studies have reported on the successful use of this supplement for different types of cells, including MSCs [4, 6-11]. However, none of these studies have addressed different sources to produce AB HS or con-

\section{KARGER}

() 2017 S. Karger GmbH, Freiburg

Fax +497614520714 
ducted a more in-depth characterization of this product. Considering that well-characterized media supplements are essential to maintaining the cellular qualities required for the intended clinical application [6], the aim of this study was to evaluate two plasma sources for $\mathrm{AB} \mathrm{HS}$ production regarding their biochemical profile, quality parameters, and efficacy to support MSC growth after different storage times $(0,3,6,9$, and 12 months).

\section{Material and Methods}

\section{Plasma Selection and AB HS Production}

For the AB HS production, $\mathrm{AB}$ plasma removed from whole blood after $24 \mathrm{~h}$ of collection ( $\mathrm{PC}>24 \mathrm{~h}$ ) and $\mathrm{AB}$ plasma cryoprecipitate reduced (PCryoR) from donations provided by the Regional Blood Center of Ribeirão Preto, Brazil, were selected in compliance with the consent and approval of the Ethics Committee from the Central Hospital, Ribeirão Preto Medical School, University of São Paulo (HCFMRP-USP) (CAAE: 15694613.5.1001.5440). PC > $24 \mathrm{~h}$ equals plasma whose freezing process did not meet the technical specifications for therapeutic use which require fractionation within $18 \mathrm{~h}$ and storage at $-20^{\circ} \mathrm{C}$ within $24 \mathrm{~h}$. PC $>24 \mathrm{~h}$ can be fractionated and maintained at room temperature for up to $24 \mathrm{~h}$ before being stored at $-20^{\circ} \mathrm{C}$. PCryoR (also called fresh frozen, cryoprecipitate-depleted) is a byproduct of cryoprecipitate preparation $[12,13]$. Three batches of AB HS from PC $>24 \mathrm{~h}$ and 3 batches from PCryoR were produced, each one pooled from 6 different donors.

Plasma was selected according to the following characteristics: blood type $\mathrm{AB}$-positive; negative irregular antibody testing; negative serologic testing for hepatitis B (HBsAg and anti-HBc), hepatitis C, HIV type 1 and type 2, Chagas disease, syphilis, and human T cell lymphotropic virus (HTLV) type 1 and type 2; nucleic acid testing (NAT) negative for HIV, hepatitis B and C; male or female donors without a history of pregnancy in order to prevent transfusion-related acute lung injury (TRALI) reactions; visual analysis, i.e., plasma with clear appearance (not lipemic) and without hemolysis.

The production process was based on the protocol described by de Lima Prata et al. [9] with some modifications. For each batch, $6 \mathrm{AB}$ plasma units were thawed in a water bath at $37{ }^{\circ} \mathrm{C}$ and transferred to a 2-liter sterile plastic bag using 2 drips to administer intravenous solutions via a sterile connection unit. To this pooled human plasma, $\mathrm{CaCl}_{2}(0.1 \mathrm{~mol} / \mathrm{l})$ was added at a ratio of 9:1. The bag was then incubated for $180 \mathrm{~min}$ at room temperature. Afterwards, fibrin clots were removed by filtration $(170 \mu \mathrm{m})$, and the serum was transferred to a new 2 -liter bag and incubated for $48 \mathrm{~h}$ at $4{ }^{\circ} \mathrm{C}\left(2-6{ }^{\circ} \mathrm{C}\right)$. After this, AB HS was filtered again (filter $170 \mu \mathrm{m}$ ) to remove residual fibrin clots and then sterilized by filtration $(0.2 \mu \mathrm{m})$. The batches produced were stored at $-20^{\circ} \mathrm{C}$.

\section{AB HS Quality Control}

To ensure quality and reproducibility as well as to identify possible changes that could reduce the effectiveness of the $\mathrm{AB}$ HS produced, various analytical parameters were evaluated:

- Sterility regarding bacteria, fungi, and mycoplasma: Mycoplasma detection was performed using the MycoAlert ${ }^{\mathrm{TM}}$ commercial kit (Lonza, Rockland, ME, USA) according to the manufacturer's instructions. Bacteria and fungi were detected using the microbial detection blood culture system BacT/ ALERT $^{\circledR}$ (BioMérieux, Paris, France). For this analysis, $4 \mathrm{ml}$ of the produced $\mathrm{AB}$ HS were inoculated into the BacT/ALERT PF kit under sterile conditions and incubated in the BacT/ALERT system for 14 days.

- Determination of endotoxins: The Endosafe ${ }^{\circledR}$ kit (Charles River Endosafe, Charleston, SC, USA) was used according to the manufacturer's instructions to measure the endotoxin concentration.

- Serum free hemoglobin test: The level of free hemoglobin in the serum was obtained by using a Spectronic ${ }^{\circledR}$ Genesys ${ }^{\mathrm{TM}} 2 \mathrm{PC}$ spectrophotometry (Thermo Fisher Scientific, Waltham, MA, USA) and analyzed using WinSpec software.
- Biochemical analysis: Biochemical analysis was conducted by the Clinical Pathology Laboratory of the HCFMRP-USP. The measured biochemical parameters of the serum were: total protein, sodium, potassium, iron, chlorine, alkaline phosphatase, alanine transaminase (ALT), aspartate transaminase (AST), chloride, glucose, gamma glutamyl transferase (GGT), uric acid, urea, cholesterol, triglycerides, calcium, albumin, creatinine, phosphorous, total bilirubin, direct bilirubin, indirect bilirubin, lactate dehydrogenase (LDH), and osmolality.

- pH analysis: The $\mathrm{pH}$ analysis of the AB HS was performed during the supplementation of the culture medium (after AB HS freezing) using the $\mathrm{pH}$ meter ORIONTM $^{\text {TM }} 72 \mathrm{~A}+$ (Thermo Fisher Scientific, Waltham, MA, USA) .

\section{MSC Culture}

All experiments were performed using MSCs derived from umbilical cord matrix obtained from a cell bank at the Regional Blood Center of Ribeirão Preto (HPCR n¹4906/2010, HPCR 920/2009). To eliminate MSC heterogeneity among donors, MSCs were obtained from only one donor to better evaluate batch-to-batch reproducibility and to analyze the effect of plasma sources that were used for production of AB HS on MSC expansion.

MSCs were cultivated using alpha-MEM culture medium (Gibco-BRL, Gaithersburg, MD, USA) supplemented with $10 \%$ antibiotic (penicillin/streptomycin; Gibco-BRL, Gaithersburg, MD, USA), 2.6 g/l HEPES (Gibco-BRL) and $2.2 \mathrm{~g} / \mathrm{l}$ sodium bicarbonate (Merck, São Paulo, Brazil). In addition, the medium was either supplemented with 10\% FBS (Fetal Bovine Serum Characterized HyClone $^{\mathrm{TM}}$; Logan, UT, USA) (control) or with $10 \%$ of the AB HS produced for the purpose of this study. Cells cultured in $10 \% \mathrm{AB}$ HS were isolated using $\mathrm{AB}$ $\mathrm{HS}$, and cells cultured in 10\% FBS were isolated in an FBS-containing medium.

Cryopreserved cells were thawed in passage 3 and seeded at a concentration of $1.5 \times 10^{5}$ cells $/ \mathrm{ml}$ in T-flasks $\left(75 \mathrm{~cm}^{2}\right)$ with $15 \mathrm{ml}$ of the culture medium supplemented with $10 \%$ AB HS / FBS $\left(3 \times 10^{4} \mathrm{cell} / \mathrm{cm}^{2}\right)$. A monolayer culture was kept at $37^{\circ} \mathrm{C}$ in a $5 \% \mathrm{CO}_{2}$ humidified incubator and trypsinized with Tryple ${ }^{\mathrm{TM}}$ Select solution (Gibco, Grand Island, NY, USA) after reaching $80 \%$ confluence. Every 3 days, $50 \%$ of the culture medium was changed. Experiments were performed in duplicate, and the cells were monitored from the 4 th until the 7 th passage.

Cell density was determined using an automatic cell counter (MINDRAY BC-2800 Auto Hematology Analyzer; Mindray Bio-Medical Electronics Co. Ltd., Nanshan, China).

\section{MSC Characterization}

MSCs retrieved from static cultures (T-flasks) at the 7th passage after cultivation in culture media supplemented with AB HS and FBS were submitted to characterization as described in detail below.

Flow Cytometry Analysis

Cell-surface antigens were analyzed by staining, using specific monoclonal antibodies. Immunolabeling was performed according to standard indirect immunocytochemistry protocols using the primary antibodies (CD73-PE, HLAABC-FITC, CD90-PE, CD105-PerCP, CD146-FITC, CD166-PE, HLA-DRPerCP, CD31-FITC, CD34-PerCP, CD45-FITC, and CD14-PE) and corresponding isotype controls. The cells were analyzed using a FACScalibur ${ }^{\mathrm{TM}}$ flow cytometer (Becton Dickinson, San Jose, CA, USA). 10,000 events were captured and analyzed using CELLQuest ${ }^{\mathrm{TM}}$ software (Becton Dickinson).

\section{In vitro Differentiation Assays}

Adipogenic and osteogenic differentiation was performed as previously described [9]. About $4 \times 10^{4}$ cells were seeded in 24-well plates and cultivated in an expansion medium (a-MEM plus 7.5\% FBS) until almost complete confluence was reached. The following day, the medium was switched to a differentiation medium and the culture was maintained for 3 days. The medium was then changed every 2 days until day 21 for adipogenic, and day 28 for osteogenic differentiation. The culture medium for the adipogenic differentiation consisted of alpha-MEM 15\% FBS supplemented with $10 \mu \mathrm{g} / \mathrm{ml}$ insulin (Sigma-Al- 
drich, Saint Louis, MO, USA), $100 \mathrm{mmol} / \mathrm{l}$ indomethacin (Sigma-Aldrich), and $0.10 \mu \mathrm{mol} / \mathrm{l}$ dexamethasone (Sigma-Aldrich). The culture medium for osteogenic differentiation consisted of alpha-MEM 7.5\% FBS supplemented with 10 $\mu \mathrm{mol} / \mathrm{l}$ b-glycerol phosphate (Sigma-Aldrich), $100 \mu \mathrm{mol} / \mathrm{l} \mathrm{L}$-ascorbic acid (Sigma-Aldrich), and $10 \mu \mathrm{mol} / \mathrm{l}$ dexamethasone. For chondrogenic differentiation, $1 \times 10^{7}$ cells were plated in droplets $(10 \mu \mathrm{l})$ on Ultra-Low Attachment multiwell plates (Corning, Lowell, MA, USA). The plates were left in the incubator for $30 \mathrm{~min}$. Afterwards, Dulbecco's Modified Eagle's Medium (DMEM) was supplemented with $100 \mathrm{mmol} / \mathrm{l}$ sodium pyruvate, $20 \%$ albumin, $20 \mathrm{mmol} / \mathrm{l}$ ascorbic acid and $1 \mathrm{mmol} / \mathrm{l}$ of dexamethasone. After 15 days, cells were fixed with paraformaldehyde (4\%) for $30 \mathrm{~min}$, washed twice with PBS and stained with Alcian blue (1\%, Sigma-Aldrich) for $2 \mathrm{~h}$ to assess proteoglycan synthesis.

\section{Inhibition of T-Lymphocyte Proliferation}

The inhibition of T-lymphocyte proliferation potential was assessed with cells cultured in AB HS / FBS in 24-well plates (triplicate). Peripheral blood mononuclear cells (PBMCs), stained with $2.5 \mathrm{mmol} / \mathrm{l} \mathrm{CFSE}$ (carboxyfluorescein diacetate succinimidyl ester; Molecular Probes, Eugene, OR, USA) and stimulated with 1 $\mathrm{mg} / \mathrm{ml}$ phytohemagglutinin (PHA) (Sigma-Aldrich), were co-cultured with different MSC concentrations (1:2, 1:5, and 1:10) for 5 days. Control wells consisted of CFSE-labeled PBMCs stimulated with PHA in the absence of MSCs.

At the end of the experiments, the cells were stained with CD3-APC (Becton Dickinson) and analyzed by flow cytometry. The ability of MSCs to inhibit the proliferation of $\mathrm{T}$ lymphocytes was calculated by the proliferation ratios of PBMCs cultured without or with different concentrations of MSCs.

\section{Cytogenetic Analysis}

The cytogenetic profile of the MSCs ( $n=5)$ was evaluated after 12 months of storage in alpha-MEM medium supplemented with different batches of $\mathrm{AB}$ HS. FBS-cultured cells were also submitted to conventional cytogenetic analysis. The cells were maintained in static flasks until $70 \%$ confluence was reached. $150 \mu \mathrm{l}$ colchicine $(10 \mu \mathrm{g} / \mathrm{ml})$ (Colcemid; Sigma Aldrich) was used to disrupt the cell cycle in the metaphase. The cells were harvested, underwent hypotonic treatment, were fixated, and then dropped onto glass slides. Next, they were submitted to G-banding with trypsin (Gibco) followed by Wright's eosin meth ylene blue staining (Merck, Darmstadt, Germany). For each MSC sample, images of at least 20 cells in metaphase were captured [14] and analyzed using the AXIO Imager 2 optical microscopy (Zeiss, Oberkochen, Germany) and the Applied Spectral Imaging software (Applied Spectral Imaging, Carlsbad, CA, USA); all analyzed metaphases presented a level of resolution of $\geq 550$-band stage. The karyotypes were described according to international criteria for chromosome nomenclature (International System for Human Cytogenetic Nomenclature - ISCN, 2013) [15].

\section{Statistical Analysis}

The results are presented as mean \pm standard deviation (SD). Comparisons between experimental results were determined by the Mann-Whitney test. A $\mathrm{p}$ value $<0.05$ was considered statistically significant.

\section{Results}

\section{Production and Quality Control of AB HS}

$\mathrm{PC}>24 \mathrm{~h}$ and PCryoR were used for the AB HS production. Three batches of PC $>24 \mathrm{~h}$ and 3 batches of PCryoR-derived serum were produced with a yield of $96.550 \pm 0.004 \%$ (initial pooled plasma volume / volume of AB HS obtained).

A quality evaluation was performed for all $\mathrm{AB}$ HS batches regarding sterility (bacteria and fungi), Mycoplasma detection, $\mathrm{pH}$, endotoxin, and hemoglobin levels as well as the biochemical pa- rameters usually evaluated in commercial FBS products. These analyses were also performed after 3, 6, 9, and 12 months of storage at $-20{ }^{\circ} \mathrm{C}$ to identify the shelf life of this product.

The biochemical profile (table 1) revealed that the levels of most compounds in the AB HS were different from those obtained in FBS (cholesterol, glucose, total protein, iron, potassium, chlorine, gamma GT, uric acid, AST, ALT, alkaline phosphatase, calcium, albumin, $\mathrm{LDH}$, indirect bilirubin and creatinine). The level of osmolality, an important parameter to measure homeostasis in culture media, was similar for AB HS and FBS, as were the levels of triglycerides, sodium, urea, phosphorous, and direct bilirubin. After 3, 6, 9, and 12 months of storage at $-20^{\circ} \mathrm{C}$, new biochemical profiles were obtained to identify possible changes in the AB HS composition; no significant alterations were observed (data for 3, 6 , and 9 months not shown).

The protocol for AB HS production adopted in the present study enabled the production of a sterile product without any microbiological contamination, including Mycoplasma (table 2). Furthermore, the endotoxin levels were below the level recommended by the European Pharmacopoeia $(<5.0 \mathrm{EU} / \mathrm{ml})$ and similar to the levels observed for FBS. Hemoglobin levels were also below the levels observed in FBS. These low hemoglobin levels were expected because only plasma without hemolysis and lipemia was selected for the $\mathrm{AB}$ $\mathrm{HS}$ production. The $\mathrm{pH}$ level was also similar in $\mathrm{AB} \mathrm{HS}$ and commercial FBS, even after several months of storage at $-20{ }^{\circ} \mathrm{C}$ (table 2).

Comparative Analysis of MSC Expansion Using FBS and AB HS

In this study, MSCs derived from human umbilical cord matrix, which was isolated and expanded in a culture medium supplemented with $10 \%$ AB HS, was used. As control, the same cells were isolated and cultured in a medium supplemented with 10\% FBS.

During culture, MSC morphology was monitored by phase contrast microscopy. After cell seeding, it was observed that the cells distributed homogeneously over the surface, achieving $70-80 \%$ of confluence in a short period of time. As expected, the cells showed a similar spindle-shaped morphology when cultured with 10\% FBS or $10 \% \mathrm{AB}$ HS (PC > $24 \mathrm{~h}$ and PCryoR), with an euchromatic, central and large core and an abundant cytoplasm (fig 1A, B, C).

The doubling time (DT) and cumulative population doubling (CPD) after 4 passages in the produced serum batches ( $\mathrm{PC}>24 \mathrm{~h}$ and PCryoR) as well as in the control culture (FBS, $n=6$ ) are presented in figure $1 \mathrm{D}$ and figure 2 . Relevant differences $(\mathrm{p}>0.05$, Tukey-Kramer test) were not observed regarding the CPD, DT and final increase of MSC expansion in the culture medium supplemented with $\mathrm{AB}$ HS when compared to the FBS control medium (table 3). There were also no differences between AB HS, PCryoR and $\mathrm{PC}>24 \mathrm{~h}$.

The efficacy of AB HS supplementation was evaluated after different storage times $(0,3,6,9$, and 12 months) (fig. 3). The results show that there were no significant differences in MSC growth, leading us to the conclusion that the shelf life for AB HS may be at least 12 months. 
Table 1. Biochemical profile of $A B$ HS batches $\mathrm{PC}>24 \mathrm{~h}$ (batches $1-3$ ) and PCryoR (batches $4-6$ ) right after production and after 12 months of storage at $-20{ }^{\circ} \mathrm{C}$

\begin{tabular}{|c|c|c|c|c|c|c|c|c|c|c|c|c|c|}
\hline & \multicolumn{6}{|c|}{ AB HS PC $>24 h$ batches } & \multicolumn{6}{|c|}{ AB HS PCryoR batches } & \multirow[t]{3}{*}{ FBS $^{*}$} \\
\hline & \multicolumn{2}{|l|}{1} & \multicolumn{2}{|l|}{2} & \multicolumn{2}{|l|}{3} & \multicolumn{2}{|l|}{4} & \multicolumn{2}{|l|}{5} & \multicolumn{2}{|l|}{6} & \\
\hline & $t_{0}$ & $t_{12}$ & $t_{0}$ & $t_{12}$ & $t_{0}$ & $t_{12}$ & $t_{0}$ & $t_{12}$ & $\mathrm{t}_{0}$ & $t_{12}$ & $t_{0}$ & $t_{12}$ & \\
\hline Cholesterol, mg/dl & 124 & 131 & 147 & 149 & 122 & 127 & 123 & 102 & 134 & 138 & 165 & 158 & 34 \\
\hline Triglycerides, mg/dl & 86 & 87 & 118 & 114 & 64 & 64 & 49 & 37 & 116 & 112 & 97 & 96 & 71 \\
\hline Glucose, mg/dl & 448 & 470 & 448 & 460 & 424 & 468 & 439 & 369 & 463 & 482 & 503 & 470 & 106 \\
\hline Sodium, meq/l & 136 & 139 & 136 & 139 & 137 & 139 & 142 & 123 & 141 & 142 & 144 & 141 & 125 \\
\hline Total protein, g/dl & 5.6 & 5.7 & 5.7 & 5.7 & 5.5 & 5.4 & 5.8 & 4.7 & 5.4 & 5.5 & 5.7 & 5.6 & 3.7 \\
\hline Iron, $\mu \mathrm{g} / \mathrm{dl}$ & 87 & 86 & 70 & 74 & 70 & 78 & 83 & 72 & 94 & 104 & 89 & 94 & 197 \\
\hline Potassium, meq/l & 4.3 & 4.4 & 4.6 & 4.6 & 4.6 & 4.7 & 2.9 & 2.5 & 2.8 & 2.9 & 3.0 & 3.0 & 12.1 \\
\hline Chlorine, meq/l & 80.1 & 84.0 & 81.1 & 85.2 & 81.4 & 85.7 & 80.9 & 68.1 & 81.9 & 86.0 & 78.7 & 85.0 & 98.5 \\
\hline GGT, U/1 & 35 & 36 & 17 & 18 & 25 & 26 & 17 & 15 & 18 & 18 & 27 & 27 & 6 \\
\hline Uric acid, mg/dl & 5.7 & 5.7 & 4.6 & 4.6 & 5.5 & 5.6 & 4.9 & 4.2 & 4.9 & 4.9 & 4.9 & 4.9 & 2.1 \\
\hline ALT, U/l & 7.4 & 19.6 & 10.1 & 14.4 & 23.8 & 24.5 & 11.3 & 11.3 & 13.6 & 13.7 & 17.7 & 18.6 & 6.3 \\
\hline Alkaline phosphatase , U/l & 78 & 102 & 104 & 97 & 117 & 126 & 80 & 77 & 111 & 92 & 130 & 107 & 513 \\
\hline Urea, $\mathrm{mg} / \mathrm{dl}$ & 34 & 31 & 25 & 24 & 29 & 27 & 30 & 25 & 23 & 21 & 29 & 29 & 31 \\
\hline Calcium, mg/dl & 45.2 & 46.7 & 44.1 & 43.4 & 43.5 & 43.7 & 43.8 & 35.1 & 44.3 & 43.2 & 45.4 & 45.4 & 13.1 \\
\hline Osmolality, mOsm/kg & 303 & 310 & 303 & 308 & 303 & 309 & 345 & 271 & 312 & 315 & 321 & 314 & 261 \\
\hline Phosphorus, mg/dl & 10.4 & 10.8 & 10.5 & 11.1 & 10.0 & 10.4 & 10.7 & 9.1 & 10.2 & 10.6 & 10.4 & 10.9 & 10.4 \\
\hline Albumin, g/dl & 3.8 & 3.6 & 3.7 & 3.6 & 3.7 & 3.6 & 3.8 & 3.1 & 3.7 & 3.6 & 3.8 & 3.8 & 2.4 \\
\hline $\mathrm{LDH}, \mathrm{U} / \mathrm{l}$ & 348 & 378 & 305 & 297 & 327 & 342 & 507 & 415 & 299 & 294 & 278 & 281 & 871 \\
\hline Direct bilirubin, mg/dl & 0.12 & 0.13 & 0.08 & 0.11 & 0.09 & 0.10 & 0.14 & 0.13 & 0.08 & 0.11 & 0.11 & 0.12 & 0.07 \\
\hline Indirect bilirubin, $\mathrm{mg} / \mathrm{dl}$ & 0.35 & 0.32 & 0.29 & 0.25 & 0.31 & 0.28 & 0.51 & 0.33 & 0.26 & 0.25 & 0.40 & 0.37 & 0.09 \\
\hline Total bilirubin, mg/dl & 0.47 & 0.45 & 0.38 & 0.36 & 0.40 & 0.39 & 0.65 & 0.46 & 0.34 & 0.36 & 0.51 & 0.49 & 0.16 \\
\hline Creatinine, mg/dl & 0.93 & 0.98 & 0.84 & 0.89 & 0.93 & 0.97 & 1.00 & 0.83 & 0.92 & 0.95 & 1.02 & 0.99 & 2.7 \\
\hline
\end{tabular}

${ }^{*}$ FBS (HyClone) biochemical profile was done using the same methodology as applied in the AB HS batches.

Table 2. Quality control of AB HS batches PC $>24 \mathrm{~h}$ (batches 1-3) and PCryoR (batches 4-6)

\begin{tabular}{|c|c|c|c|c|c|c|c|}
\hline & \multicolumn{3}{|c|}{ AB HS PC $>24$ h batches } & \multicolumn{3}{|c|}{ AB HS PCryoR batches } & \multirow[t]{2}{*}{ FBS $^{*}$} \\
\hline & 1 & 2 & 3 & 4 & 5 & 6 & \\
\hline Bacteria and fungi & neg & neg & neg & neg & neg & neg & neg \\
\hline Mycoplasma & neg & neg & neg & neg & neg & neg & neg \\
\hline Endotoxin (EU/ml) & 0.382 & 0.306 & 0.358 & 0.306 & 0.314 & 0.326 & 0.500 \\
\hline Hemoglobin (mg/dl) & $<3.92$ & 3.92 & 3.92 & $<3.92$ & $<3.92$ & $<3.92$ & 11 \\
\hline $\mathrm{pH}\left(\mathrm{t}_{0}\right)$ & 7.72 & 7.85 & 7.70 & 7.67 & 7.92 & 7.68 & 7.15 \\
\hline $\mathrm{pH}\left(\mathrm{t}_{3}\right)$ & 7.72 & 7.84 & 7.74 & 7.80 & 7.88 & 7.84 & n.d. \\
\hline $\mathrm{pH}\left(\mathrm{t}_{6}\right)$ & 7.83 & 7.98 & 8.18 & 7.93 & 8.09 & 7.89 & n.d. \\
\hline $\mathrm{pH}\left(\mathrm{t}_{9}\right)$ & 7.80 & 7.83 & 8.01 & 7.90 & 7.89 & 7.85 & n.d. \\
\hline $\mathrm{pH}\left(\mathrm{t}_{12}\right)$ & 7.61 & 7.69 & 7.73 & 7.98 & 7.69 & 7.69 & n.d. \\
\hline
\end{tabular}

Neg = negative; n.d. $=$ not determined.

${ }^{*}$ FBS (HyClone) quality control was done using the same methodology as applied in the AB HS batches.

\section{Cell Characterization after Expansion}

The expression of MSC surface antigens was assessed by flow cytometry after culturing of MSCs in medium supplemented with FBS or AB HS from PCryoR or PC $>24 \mathrm{~h}$. The results demonstrated that there were no significant differences between the tested medium supplements regarding cell markers. The cells showed a low or no expression of hematopoietic cell markers (CD34, CD14, CD45), endothelial cells (CD31) and HLA-DR; however, there was a significant expression of other cell markers, albeit at different lev-
Table 3. Comparison of total cell number obtained per passage (passages $5-7)$; seeded at $3 \times 10^{4} \mathrm{cell} / \mathrm{cm}^{2}\left(2.25 \times 10^{6}\right.$ cells $)$

\begin{tabular}{llll}
\hline Passage & FBS $(\mathrm{n}=30)$ & $\begin{array}{l}\text { AB HS PC }>24 \\
(\mathrm{n}=30)\end{array}$ & $\begin{array}{l}\text { AB HS PCryoR } \\
(\mathrm{n}=30)\end{array}$ \\
\hline P5 & $3.75 \pm 1.41 \times 10^{6}$ & $3.96 \pm 1.27 \times 10^{6}$ & $4.25 \pm 1.07 \times 10^{6}$ \\
P6 & $3.37 \pm 1.32 \times 10^{6}$ & $4.48 \pm 1.11 \times 10^{6}$ & $4.93 \pm 1.17 \times 10^{6}$ \\
P7 & $4.25 \pm 1.35 \times 10^{6}$ & $4.13 \pm 1.45 \times 10^{6}$ & $4.99 \pm 1.67 \times 10^{6}$ \\
\hline
\end{tabular}



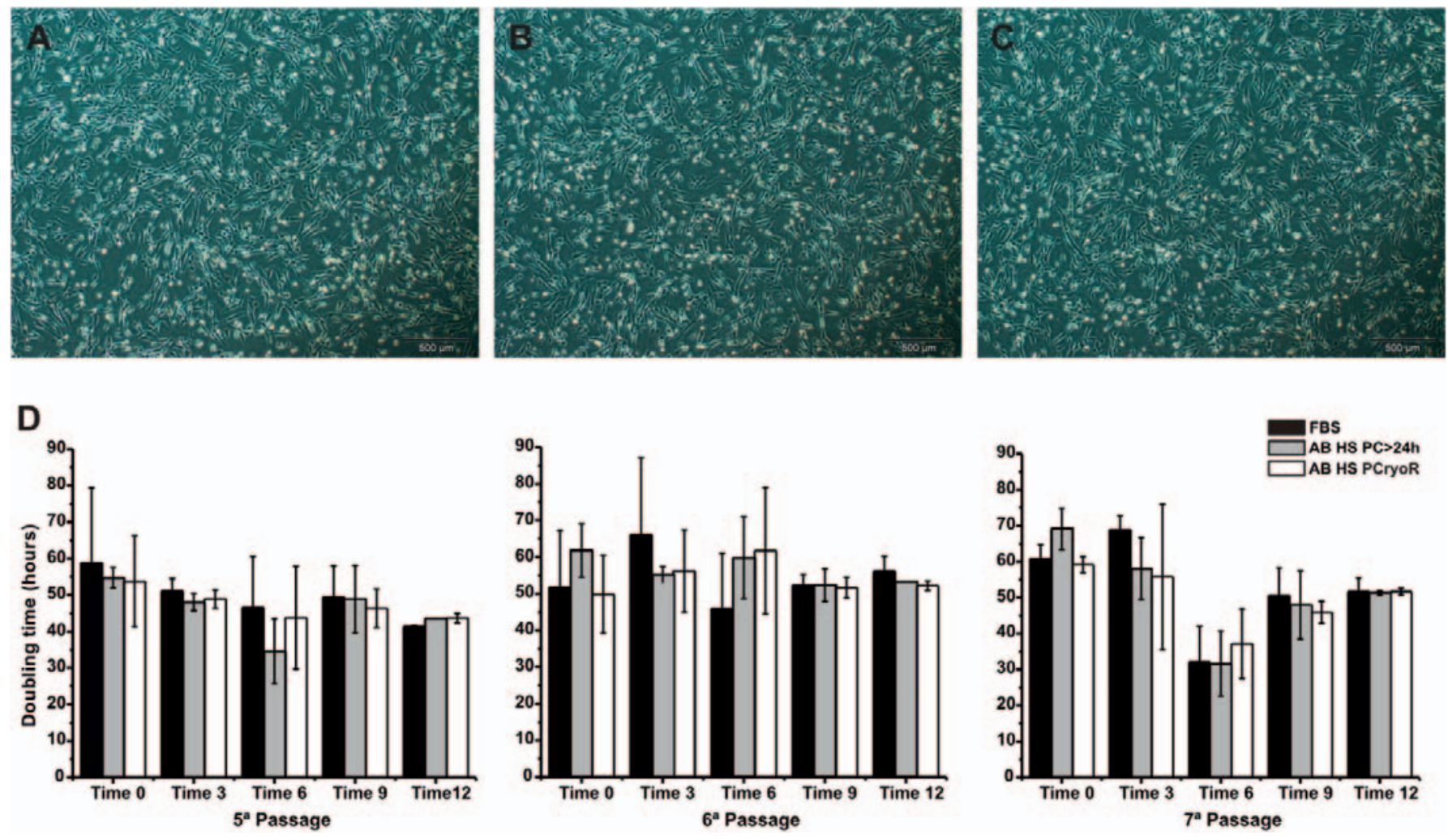

Fig. 1. MSC morphology cultured in AB HS from PCryoR $(\mathbf{A})$ and $P C>24 \mathrm{~h}(\mathbf{B})$ and FBS (C); (D) DT of MSCs grown during passages 5-7 in culture medium supplemented with FBS $(n=6)$ and AB HS batches $(n=12)$ with different post-production storage times $(0,3,6,9$ and 12 months). Results shown as mean \pm SD.

els of intensity (CD90, CD73, CD105, CD146, CD166 and HLA$\mathrm{ABC}$ ) (fig. 4).

In addition, MSCs at passage 7 were evaluated regarding their potential to inhibit T-lymphocyte proliferation after 12 months of $\mathrm{AB}$ HS storage at $-20^{\circ} \mathrm{C}$. For this purpose, PBMCs stained with CFSE and stimulated with PHA were co-cultivated with different concentrations of MSCs (1:2, 1:5 and 1:10). The obtained results were compared with those of MSCs cultivated in the presence of FBS. As shown in figure 4, post-culture MSCs were able to inhibit T-lymphocyte proliferation in a dose-dependent manner. The degree of inhibition was proportional to the ratio of MSCs:PBMCs in the co-culture. No statistical differences ( $\mathrm{p}<0.05$, ANOVA test) were observed in the percentage of T-lymphocyte inhibition between the culture medium supplemented with $\mathrm{AB}$ HS (PCryoR / $\mathrm{PC}>24 \mathrm{~h}$ ) and FBS in all tested conditions.

In MSCs at passage 7 cultivated with $\mathrm{AB}$ HS and stored for 0, 3, 6,9 , or 12 months, adipocyte or osteocyte differentiation was induced (fig. 5). The results demonstrated osteogenic and adipogenic differentiation as shown by deposits of calcium (20 days) detected via the von Kossa staining method, and by the presence of lipid vacuoles ( 13 days) detected by the Sudan II scarlet staining method (fig. 5), respectively.

Cytogenetic analyses were performed after 12 months of storage at $-20{ }^{\circ} \mathrm{C}$ using MSCs cultured in medium containing $10 \%$ FBS and those cultured in medium supplemented with different batches of $\mathrm{AB}$ HS. A representative karyotype of one metaphase is illus- trated in figure 6. The cells presented a normal karyotype without chromosomal abnormalities even after 12 months of storage.

\section{Discussion}

In this study, we produced AB HS and characterized it regarding the biochemical profile and quality parameters. The human blood group $\mathrm{AB}$ is considered to be the most reasonable choice for serum production due to its lack of $\mathrm{ABO}$ antibodies, therefore avoiding harmful reactions [16, 17]. Two plasma sources were evaluated for AB HS production: $\mathrm{PC}>24 \mathrm{~h}$ and PCryoR. These sources were selected because there is no clinical indication for these products, i.e., they are sent to the blood fractionation industry or discarded. The yield of the production was $96.550 \pm 0.004 \%$, which is higher than the yield obtained for platelet lysate (PL) production (84\%), another blood-derived component widely used for MSC growth [18].

All produced $\mathrm{AB}$ HS batches presented a similar biochemical profile, regardless of source plasma and storage time. Some differences were observed with regard to AB HS and FBS composition, as was to be expected since they are obtained from different species via different methods. Glucose and calcium levels were higher in $\mathrm{AB} \mathrm{HS}$, probably due to the volume of $0.1 \mathrm{~mol} / \mathrm{l} \mathrm{CaCl}_{2}$ added to the plasma pool (1:9) during the conversion from plasma into serum. It is also possible that the dextrose of the citrate phosphate dextrose 
A

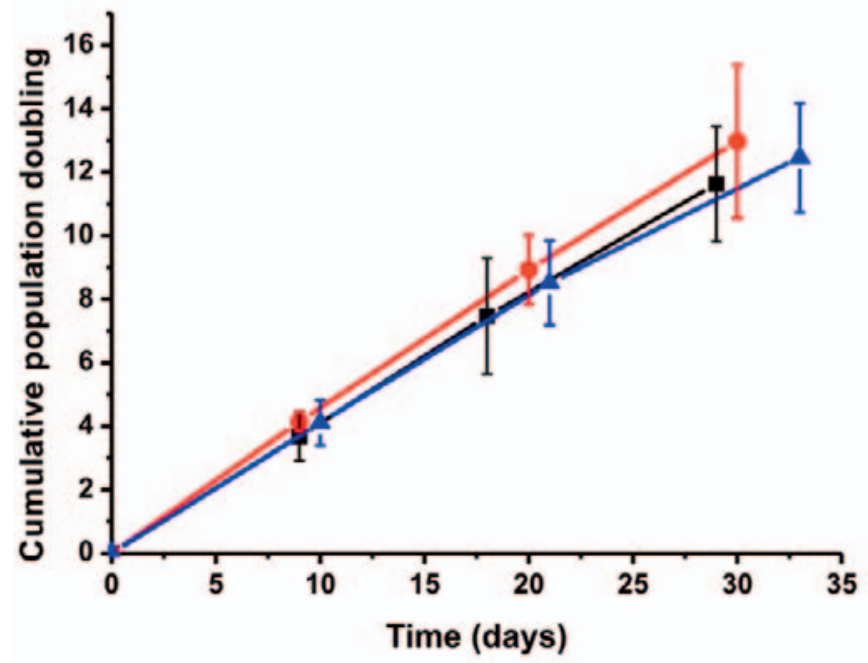

C

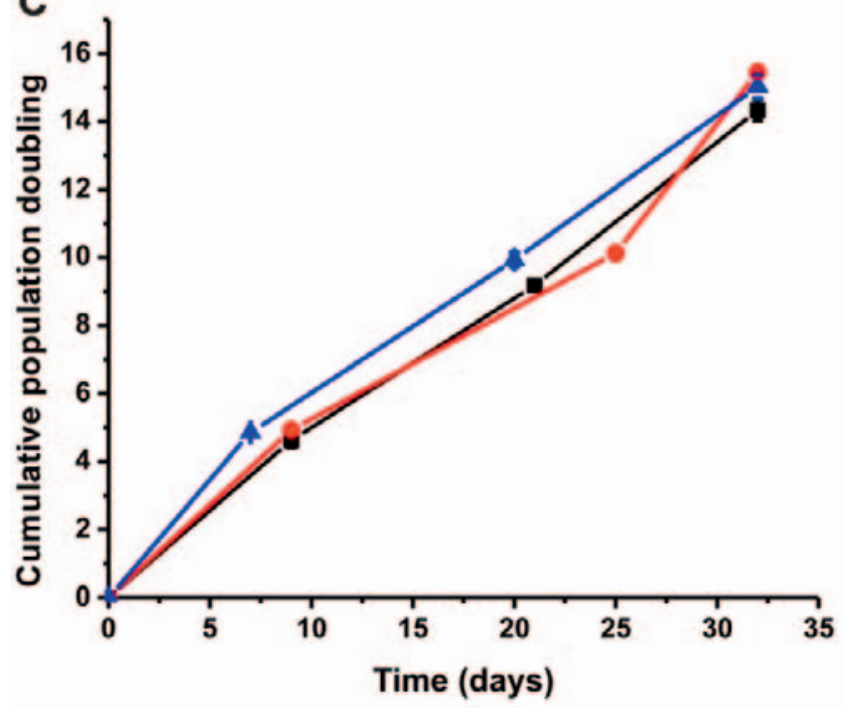

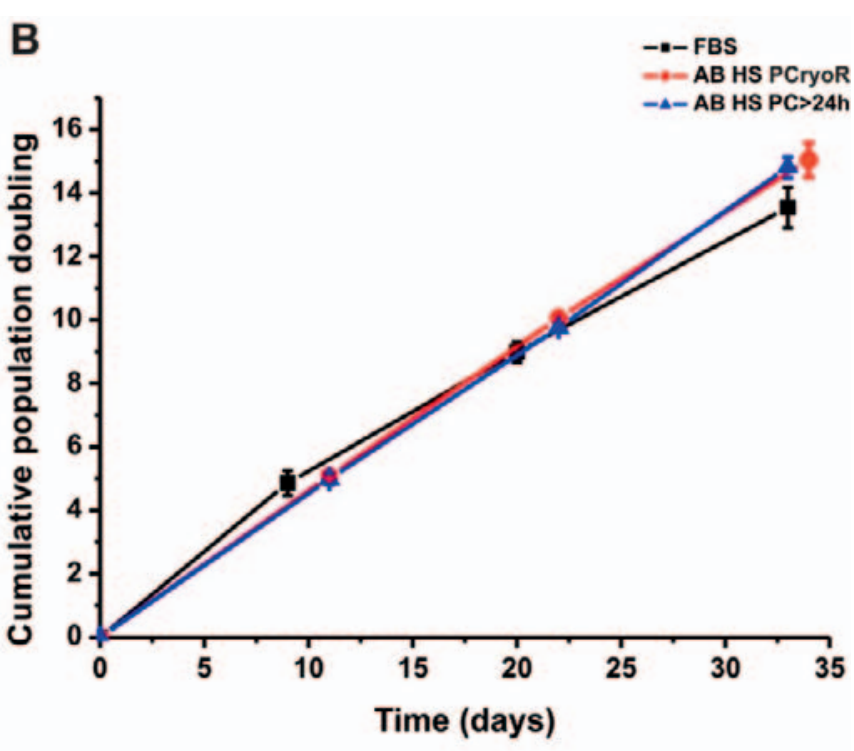

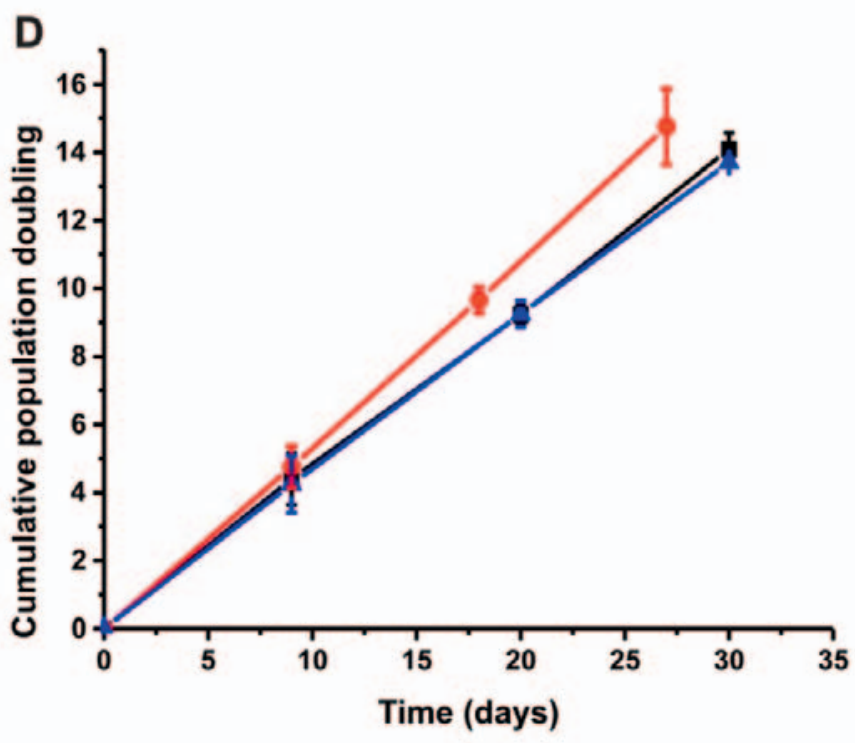

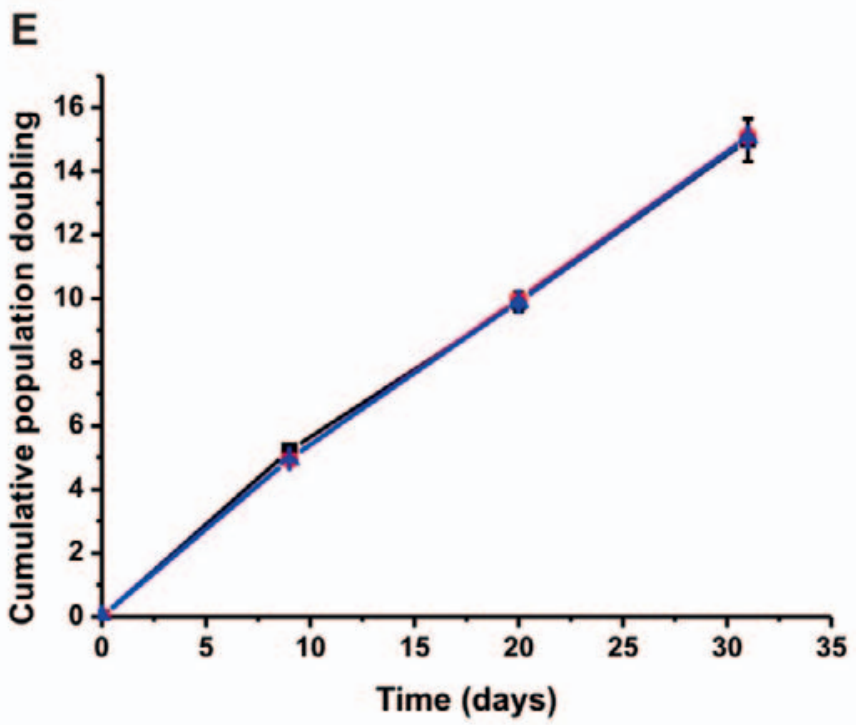

Fig. 2. Growth kinetics of MSC using culture medium supplemented with FBS and AB HS batches right after production (A) and after 3 (B), 6 (C), 9 (D) and 12 months $(\mathbf{E})$ of storage at $-20{ }^{\circ} \mathrm{C}(\mathrm{n}=6)$. Results shown as mean $\pm \mathrm{SD}$. 
A

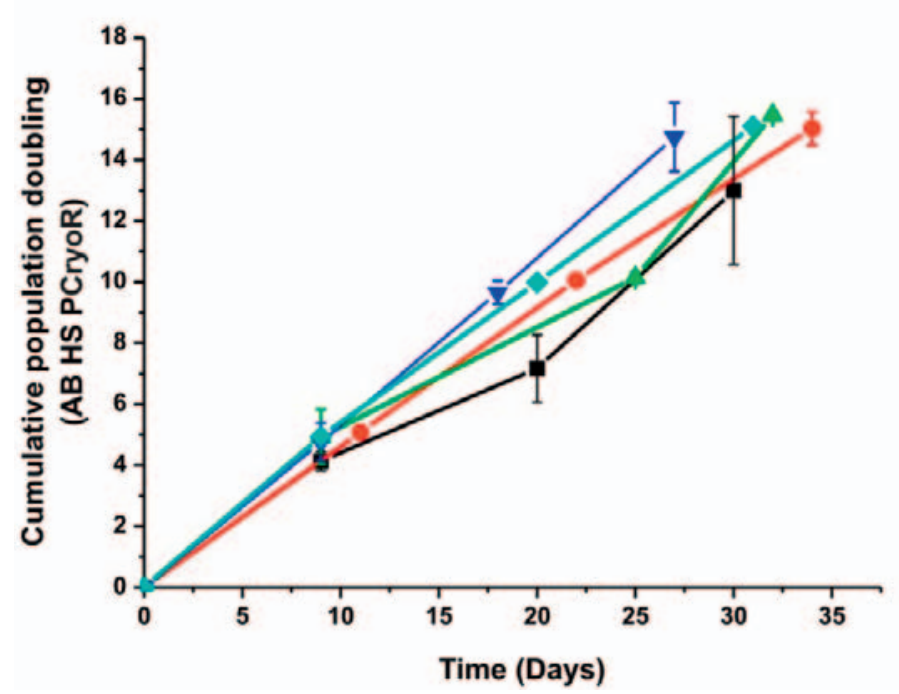

B

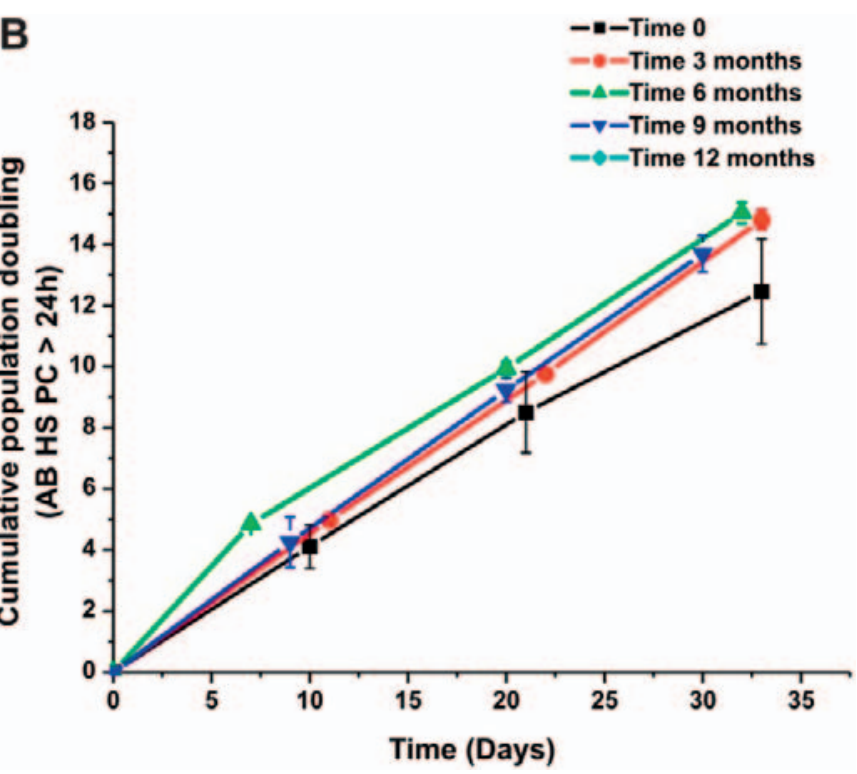

Fig. 3. Evaluation of the effect of AB HS storage time in the MSC growth obtained from (A) PCryoR $(n=6)$ and $(B) P C>24(n=6)$. Results shown as mean \pm SEM.

A

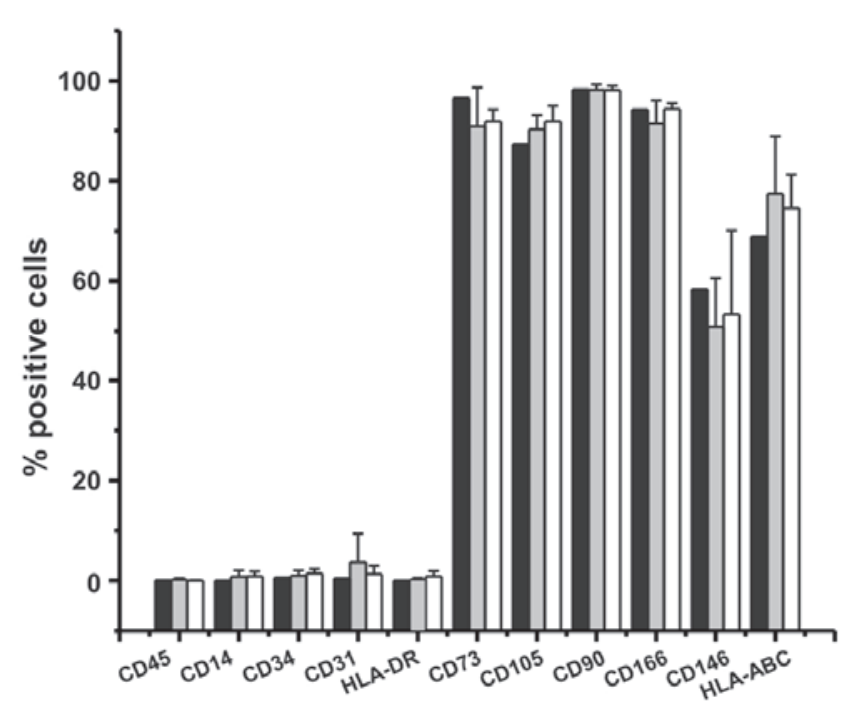

B

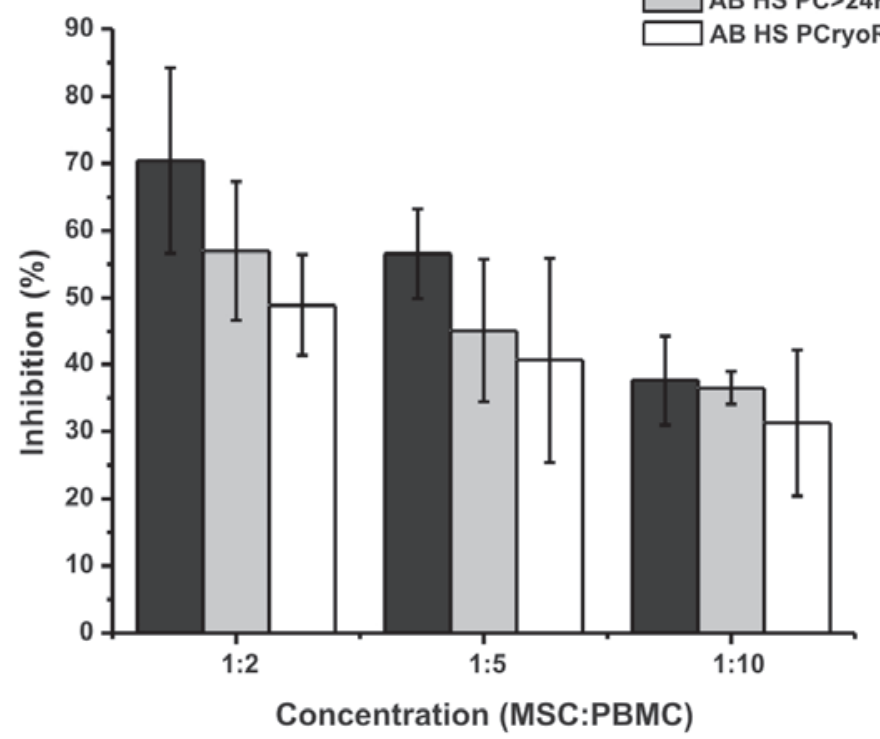

Fig. 4. Immunophenotypic profile and inhibition of T-lymphocyte proliferation of MSC cultured in the culture medium supplemented with FBS ( $\mathrm{n}=3$ ) and $\mathrm{AB}$ HS obtained from PCryoR $(n=3)$ and PC $>24 h(n=3)$ after 12 months of storage. Results shown as mean \pm SD.

adenine (CPDA-1) solution, which was added to the plasma, contributed to the considerable increase in glucose in the serum batches. As mentioned in the 'Material and Methods' section, the AB HS were obtained from donor plasma bags, where 60-65 $\mathrm{ml}$ of CPDA- 1 were added for each $450 \pm 50 \mathrm{ml}$ of whole blood. The increased glucose concentration of AB HS was responsible for a $24 \%$ increase in the glucose concentration of the supplemented culture medium when compared to the medium supplemented with FBS: $248.5 \pm 9.2$ versus $187.0 \pm 6.9 \mathrm{mg} / \mathrm{dl}$. The biochemical profile of $\mathrm{AB}$ HS was similar to the one of a healthy person (data from Central Laboratory, HCFMRP-USP).
Additionally, all AB HS batches met the quality standards necessary to be used in the manufacturing of cell-based products. The use of blood bank-derived plasma adds to the serum quality due to the careful screening of donors required by current legislation (Brazil, Regulatory Ordinance No. 2712 of November 12, 2013), which decreases lot-to-lot variability. In addition, only quarantine plasma, i.e., plasma released after a second serology which is performed when a second donation is received, is used, improving product safety. Another advantage of using blood bank-derived plasma is the availability of serological and molecular assays. In this study, serological assays were performed for hepatitis B 

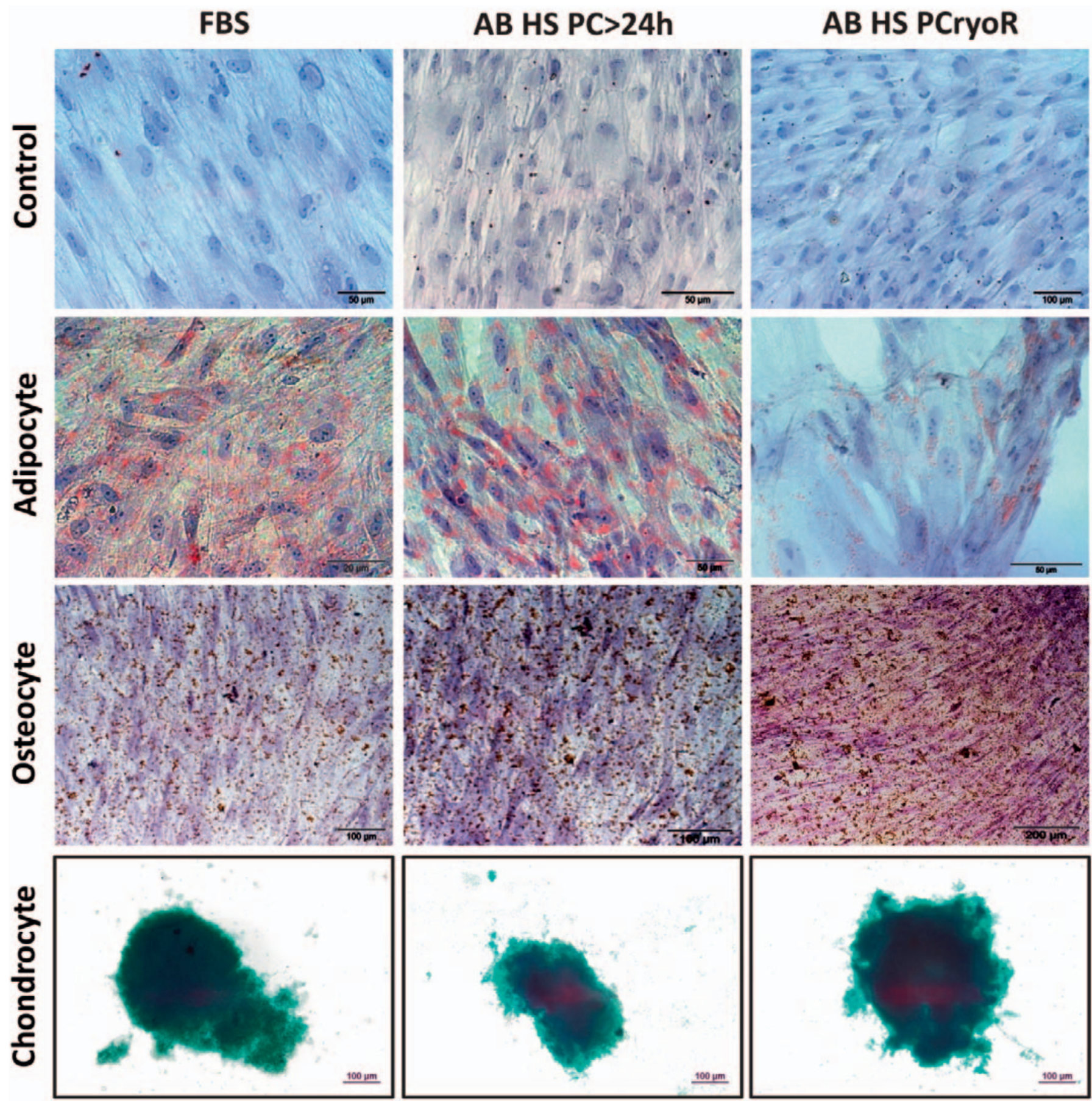

Fig. 5. Cell differentiation of MSCs cultivated with FBS, AB HS PC > 24 h, or AB HS PCryoR and stored for different times $0,3,6,9$ and 12 months. Differentiation of MSCs to adipocytes, osteocytes, and chondrocytes was induced.

(HBsAg and anti-HBc), hepatitis C, HIV type 1 and type 2, Chagas disease, syphilis, and HTLV type 1 and type 2; in addition NAT was used for HIV, hepatitis $C$, and hepatitis $B$. In the commercial AB HS product available (Mediatech Inc., Manassas, VA, USA), only serological assays for HIV type 1 and 2, hepatitis B, hepatitis C, HIV antigen (HIV-1 Ag), and ALT are performed.

Microbiological contamination is one of the major risks associated with the administration of cell-based products. Therefore, it is necessary to ensure the safety and quality of the reagents used to prepare the culture medium, and to carefully overview the expansion process. Mycoplasma contamination is a major problem due to the fact that these organisms are resistant to most antibiotics commonly used in cell culture and that they cannot be seen by the naked eye or even light microscopy. Mycoplasma contamination can produce a myriad of different effects and can cause dramatic alterations of biological characteristics of the contaminated cells, e.g., alteration of proliferation characteristics, immune reactions, virus proliferation, or chromosomal aberrations, affecting a pa- 
Fig. 6. A representative karyotype of MSC culture on alpha-MEM culture medium supplemented with $A B$ HS (12 months of storage). Analysis of 20 metaphases revealed 46,XX The karyogram illustrated in the figure presents a level of resolution of 625-band stage.
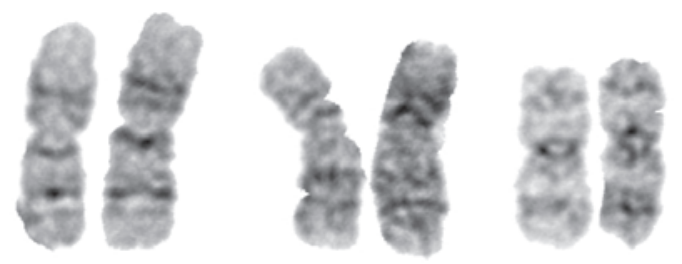

3
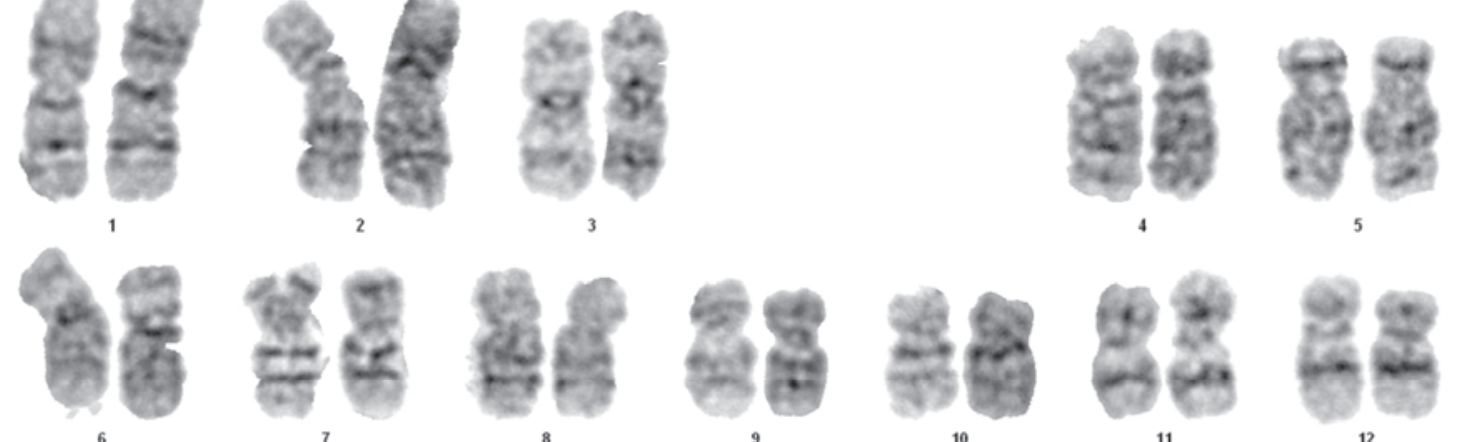

10

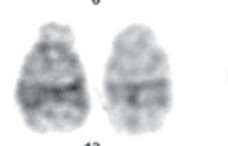

13
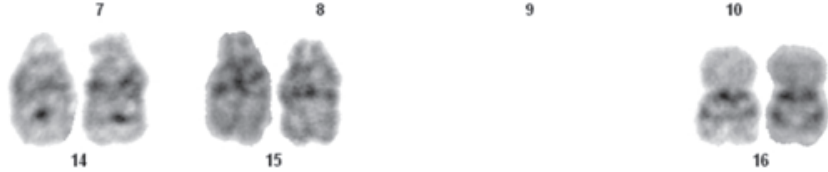

16

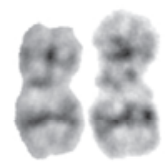

11

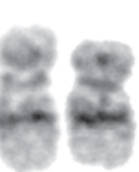

12
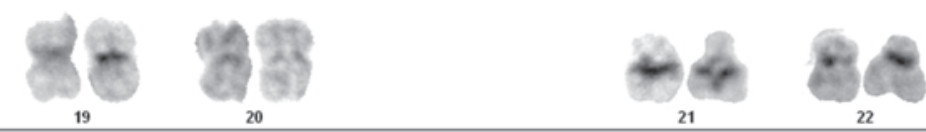

22 tient's health [19]. An endotoxin assay is another requirement for cell-based products; an absence of bacterial endotoxins in a product implies the absence of pyrogenic components. Moreover, endotoxin can induce contractile dysfunction and increased production of immunoglobulin light chains [19].

The use of AB HS in cell therapy is only recently introduced and therefore the feasibility of its production as well as the quality parameters and the effectiveness to promote cell growth should be evaluated. AB HS produced from both plasma sources (PC $>24 \mathrm{~h}$ and PCryoR) was able to equally support MSC cell growth. Moreover, DT and CPD obtained for AB HS cultures were similar to the ones of the FBS-supplemented culture. A decrease in the number of cells obtained from passages 5 to 7 was not observed (table 3 ). Simões and colleagues [20] observed a reduction in the cell yield when MSCs from different sources (adipose tissue, bone marrow, and umbilical cord matrix) were cultured when comparing xenofree (commercial) and serum-containing medium throughout the passages 3 to 7. Prata [21] described the expansion of MSCs in static conditions using culture media supplemented with AB HS and PL and found no significant differences. Kokaoemer and coworkers [8] also showed the successful proliferation of adipose tissue-derived MSCs (AT-MSCs) cultured in pooled AB HS and thrombin-activated platelet-rich plasma (tPRP), demonstrating a significantly greater proliferative effect of $A B$ HS and tPRP when compared to FBS (standard control). In the first 6 passages, ATMSCs in TPRP and AB HS showed an expansion of $68.1 \pm 6.7$ and $66.6 \pm 15.7$, respectively, compared with $24.4 \pm 0.7$ for FBS. The authors promoted pooled $\mathrm{AB}$ serum as the optimal choice considering how easy it is to prepare and the fact that further additives, such as heparin and thrombin in TPRP, are not necessary. Other authors have also reported the efficacy of MSC culture using a supplementation with $\mathrm{AB}$ HS $[6,10,22,23]$. However, there are no reports evaluating different sources to obtain $\mathrm{AB}$ HS or the influ- ence of storage time on quality and efficacy of this supplement. In this study, there were no significant differences with respect to MSC growth between the culture medium right after supplementation with the newly produced AB HS, and after storage for up to 12 months at $-20^{\circ} \mathrm{C}$, indicating that the shelf life is at least 12 months (fig. 3). The FBS and PL shelf life is 5 years and 18 months, respectively [1].

Considering the serum sources, some studies stated that using autologous serum as culture medium supplementation provides a better MSC expansion when compared to culture media supplemented with allogeneic serum $[6,11]$. However, the amount of autologous serum is limited, and a large part of it is needed for clinical applications. It has been suggested that the natural coagulated serum is more effective than plasma for cell proliferation due to the release of certain polypeptides and growth factors from activated platelets during the coagulation process $[24,25]$. Nevertheless, neither fresh serum nor natural coagulated serum are common and broadly available blood bank-derived products. A unique donor would be needed to obtain coagulated serum, and the costs for processing this serum and performing additional tests would exceed the costs of obtaining plasma, since quality controls required for the latter are already part of the routine blood processing.

Another approach described in the literature involves the use of chemically defined serum-free media for MSC culture [26-29], therefore reducing batch-to-batch variability. Although a promising alternative, this culture does not maintain an expansion pattern similar to that obtained in cultures supplemented with serum [26, 27]. PL thus far can be considered the most used supplement for GMP-compliant MSC expansion instead of FBS. Several studies have demonstrated the efficacy of PL in supporting MSC cell growth [21, 30-34]. Heathman and colleagues [34] have shown that PL can be even better than FBS, delivering an increased cell growth in monolayer and also in microcarrier culture. 
After expansion in AB HS, MSCs presented an immunophenotype profile and a differentiation potential similar to that obtained in the FBS-supplemented culture. Some authors have described that MSCs cultured in FBS were more effective to inhibit T-lymphocyte proliferation than cells grown in PL [22]. Abdelrazik and colleagues [35] showed that MSCs cultivated in a culture medium supplemented with PL presented some alterations in the superficial molecules, leading to a decrease in the inhibition capacity on $\mathrm{T}$ cells and in the proliferation of NK cells when compared to the standard supplement FBS. In this study, no statistically significant differences in the percentage of T-lymphocyte inhibition between the culture medium supplemented with AB HS (PCryoR, PC > 24 h) and the one supplemented with FBS were observed. There are no reports describing the MSC capacity in inhibiting T-lymphocyte proliferation when cultured in the presence of $\mathrm{AB}$ HS.

MSCs may acquire genetic changes when cultivated in vitro, and conventional karyotyping can be considered a valuable and useful technique to analyze chromosomal stability [14]. As reported by other authors [36, 37], MSCs expanded in AB HS also presented a normal karyotype after cultivation. Chromosomal abnormalities in the MSCs could affect the health of a patient when infused.

\section{Conclusions}

The protocol used for obtaining AB HS was effective because it allowed batch-to-batch reproducibility while maintaining the qual- ity and sterility of the final product. Both plasma sources, $\mathrm{PC}>24$ $\mathrm{h}$ and PCryoR, used for the AB HS production showed similar characteristics regarding their biochemical constituents and other analytical parameters, and were effective as a culture medium supplement for the expansion of MSCs. The culture medium supplementation with $10 \%$ AB HS successfully supported the MSC expansion when compared to the control culture (10\% FBS), while maintaining immunophenotype, functional features, and cytogenetic profile. Overall, the results indicate that $\mathrm{AB}$ HS is an efficient FBS substitute and can be used without impairing the cell proliferation and quality for at least 12 months after production when stored at $-20^{\circ} \mathrm{C}$.

\section{Acknowledgments}

This work was financially supported by the CTC - Center for Cell-Based Therapies (FAPESP 2013/08135-2) as well as the National Institute of Science and Technology in Stem Cell and Cell Therapy (CNPq 573754-2008-0 and FAPESP 2008/578773). The authors acknowledge Patricia Viana Bonini for the technical assistance in using the flow cytometer.

\section{Disclosure Statement}

The authors declare no conflict of interest.

\section{References}

1 Shih DT, Burnouf D: Preparation, quality criteria, and properties of human blood platelet lysate supplements for ex vivo stem cell expansion. N Biotechnol 2015;32: 199-211.

2 Dimarakis I, Levicar N: Cell culture medium composition and translational adult bone marrow-derived stem cell research. Stem Cells 2006;24:1407-1408.

3 Laitinen A, Oja S, Kilpinen L, Kaartinen T, Moller J, Laitinen S, Korhonen M, Nystedt J: A robust and reproducible animal serum-free culture method for clinical-grade bone marrow-derived mesenchymal stromal cells. Cytotechnology 2016;68:891-906.

4 Witzeneder K, Lindenmair A, Gabriel C, Höller K, Thei D, Red H, Hennerbichler, S: Human-derived alternatives to fetal bovine serum in cell culture. Transfus Med Hemother 2013;40:417-423.

5 Bieback K: Platelet lysate as replacement for fetal bovine serum in mesenchymal stromal cell cultures. Transfus Med Hemother 2013;40:326-335.

6 Aldahmash A, Haack-Sorensen M, Al-Nbaheen M, Harkness L, Abdallah BM, Kassem M: Human serum is as efficient as fetal bovine serum in supporting proliferation and differentiation of human multipotent stromal (mesenchymal) stem cells in vitro and in vivo. Stem Cell Rev 2011;7:860-868.

7 Cánovas D, Bird N: Human AB serum as an alternative to fetal bovine serum for endothelial and cancer cell culture. Altex 2012;29:426-428.
8 Kocaoemer A, Kern S, Kluter H, Bieback K: Human $\mathrm{AB}$ serum and thrombin-activated platelet-rich plasma are suitable alternatives to fetal calf serum for the expansion of mesenchymal stem cells from adipose tissue. Stem Cells 2007;25:1270-1278.

9 de Lima Prata K, de Santis GC, Orellana MD, Palma PV, Brassesco MS, Covas DT: Cryopreservation of umbilical cord mesenchymal cells in xenofree conditions. Cytotherapy 2012;14:694-700.

10 Bieback K, Hecker A, Kocaomer A, Lannert H, Schallmoser K, Strunk D, Klüter H: Human alternatives to fetal bovine serum for the expansion of mesenchymal stromal cells from bone marrow. Stem Cells 2009;27: 2331-2341.

11 Stute N, Holtz K, Bubenheim M, Lange C, Blake F, Zander AR: Autologous serum for isolation and expansion of human mesenchymal stem cells for clinical use. Exp Hematol 2004;32:1212-1225.

12 Fung MK, Grossman BJ, Hillyer C, Weshoff CM (eds): Technical Manual, 18th ed. Bethesda, American Association of Blood Banks, 2014.

13 RDC BRAZIL: Regulatory Ordinance No. 2712 of November 12, 2013.

14 Barkholt L, Flory E, Jekerle V, Lucas-Samuel S, Ahnert P, Bisset L, Büscher D, Fibbe W, Foussat A, Kwa M, Lantz $\mathrm{O}$, Mačiulaitis R, Palomäki T, Schneider CK, Sensebé L, Tachdjian G, Tarte K, Tosca L, Salmikangas P: Risk of tumorigenicity in mesenchymal stromal cell-based therapies - bridging scientific observations and regulatory viewpoints. Cytotherapy 2013;15:753-759.
15 Shaffer LG, McGowan-Jordan J, Schmid M (eds): ISCN 2016. An International System for Human Cytogenetic Nomenclature, Basel, Karger, 2013.

16 Schallmoser K, Strunk D: Generation of a pool of human platelet lysate and efficient use in cell culture. Methods Mol Biol 2013;946:349-362.

17 Moll G, Hult A, Bahr LV, Alm JJ, Heldring N, Hamad OA, Stenbeck-Funke L, Larsson S, Teramura Y, Roelofs H, Nilsson B, Fibbe WE, Olsson ML, Le Blanc K: Do $\mathrm{ABO}$ blood group antigens hamper the therapeutic efficacy of mesenchymal stromal cells? PLoS ONE 2014; 9:e85040.

18 Fekete N, Gadelorge M, Furst D, Maurer C, Dausend J Fleury-Cappellesso S, Mailänder V, Lotfi R, Ignatius A, Sensebé L, Bourin P, Schrezenmeier H, Rojewski MT: Platelet lysate from whole blood-derived pooled platelet concentrates and apheresis-derived platelet concentrates for the isolation and expansion of human bone marrow mesenchymal stromal cells: production process, content and identification of active components. Cytotherapy 2012;14:540-554.

19 Gálvez P, Clares B, Bermejo M, Hmadcha A, Soria B: Standard requirement of a microbiological quality control program for the manufacture of human mesenchymal stem cells for clinical use. Stem Cells Dev 2014;23:1074-1083. 
20 Simões IN, Boura JS, dos Santos F, Andrade PZ, Cardoso CM, Gimble JM, da Silva CL, Cabral JM: Human mesenchymal stem cells from the umbilical cord matrix: successful isolation and ex vivo expansion using serum-/xeno-free culture media. Biotechnology J 2013; 8:448-458.

21 Prata KL: Análise comparativa das células mesenquimais obtidas de diferentes tecidos dos anexos fetais. Ribeirão Preto, Universidade de São Paulo, 2011.

22 Bernardo ME, Avanzini MA, Perotti C, Cometa AM, Moretta A, Lenta E, Del Fante C, Novara F, de Silvestri A, Amendola G, Zuffardi O, Maccario R, Locatelli F: Optimization of in vitro expansion of human multipotent mesenchymal stromal cells for cell-therapy approaches: further insights in the search for a fetal calf serum substitute. J Cell Physiol 2007;211:121-130.

23 Lindroos B, Aho K, Kuokkanen H, Räty S, Huhtala H, Lemponen R, Yli-Harja O, Suuronen R, Miettinen S Differential gene expression in adipose stem cells cultured in allogeneic human serum versus fetal bovine serum. Tissue Eng Part A 2010;16:2281-2294.

24 Balk SD, Levine SP, Young LL, LaFleur MM, Raymond NM: Mitogenic factors present in serum but not in plasma. Proc Natl Acad Sci U S A 1981;78:5656-5660.

25 Gospodarowicz D, Ill CR: Do plasma and serum have different abilities to promote cell growth? Proc Natl Acad Sci U S A 1980;77:2726-2730.

26 Agata H, Watanabe N, Ishii Y, Kubo N, Ohshima S, Yamazaki M, Tojo A, Kagami H: Feasibility and efficacy of bone tissue engineering using human bone marrow stromal cells cultivated in serum-free conditions. Biochem Biophys Res Commun 2009;382:353358.
27 Rodrigues M, Griffith LG, Wells A: Growth factor regulation of proliferation and survival of multipotential stromal cells. Stem Cell Res Ther 2010;1:32.

28 Mimura S, Kimura N, Hirata M, Tateyama D, Hayashida M, Umezawa A, Kohara A, Nikawa H, Okamoto T, Furue MK: Growth factor-defined culture medium for human mesenchymal stem cells. Int J Dev Biol 2011;55:181-187.

29 Chase LG, Yang S, Zachar V, Yang Z, Lakshmipathy U, Bradford J, Boucher SE, Vemuri MC: Development and characterization of a clinically compliant xenofree culture medium in good manufacturing practice for human multipotent mesenchymal stem cells. Stem Cells Transl Med 2012;1:750-758.

30 Smith JR, Pfeifer K, Petry F, Powell N, Delzeit J, Weiss ML: Standardizing umbilical cord mesenchymal stromal cells for translation to clinical use: selection of GMP-compliant medium and a simplified isolation method. Stem Cells Int 2016;2016:6810980.

31 Wuchter P, Vetter M, Saffrich R, Diehlmann A, Bieback K, Ho AD, Horn P: Evaluation of GMP-compliant culture media for in vitro expansion of human bone marrow mesenchymal stromal cells. Exp Hematol 2016;44:508-518.

32 Burnouf T, Strunk D, Koh MBC, Schallmoser K: Human platelet lysate: replacing fetal bovine serum as a gold standard for human cell propagation? Biomaterials 2016;76:371-387.

33 Escobar $\mathrm{CH}$, Chaparro O: Xeno-free extraction, culture, and cryopreservation of human adipose-derived mesenchymal stem cells. Stem Cells Transl Med 2016; 5:358-365.
34 Heathman TRJ, Stolzing A, Fabian C, Rafiq QA, Coopman K, Nienow AW, Kara B, Hewitt CJ: Scalability and process transfer of mesenchymal stromal cell production from monolayer to microcarrier culture using human platelet lysate. Cytotherapy 2016;18: 523-535.

35 Abdelrazik H, Spaggiari GM, Chiossone L, Moretta L: Mesenchymal stem cells expanded in human platelet lysate display a decreased inhibitory capacity on $\mathrm{T}$ and NK-cell proliferation and function. Eur J Immunol 2011;41:3281-3290.

36 Paula ACC, Martins TMM, Zonari A, Frade SP, Angelo PC, Gomes DA, Goes AM: Human adipose tissuederived stem cells cultured in xeno-free culture condition enhance c-MYC expression increasing proliferation but bypassing spontaneous cell transformation. Stem Cell Res Ther 2015;6:1-19.

37 Kǿlle ST, Oliveri RS, Glovinski PV, Kirchhoff M, Mathiasen AB, Elberg JJ, Andersen PS, Drzewiecki KT, Fischer-Nielsen A: Pooled human platelet lysate versus fetal bovine serum - investigating the proliferation rate, chromosome stability and angiogenic potential of human adipose tissue-derived stem cells intended for clinical use. Cytotherapy 2013;15:1086-1097. 